\title{
3-Nitrotyrosine inhibits fibroblast-mediated collagen gel contraction and chemotaxis
}

\author{
H. Sugiura*, X. Liü, T. Ichikawa*, M. Ichinose* and S.I. Rennard ${ }^{\#}$
}

\begin{abstract}
Reactive nitrogen species induce tissue inflammation and nitrate tyrosine residues of various kinds of proteins. Recent studies have established that the free amino acid form of 3nitrotyrosine induces cytotoxity and growth inhibition and alters the cellular function in cultured cells. The aim of this study was to evaluate whether 3-nitrotyrosine could affect tissue remodelling in fibroblasts. To accomplish this, human fetal lung fibroblasts (HFL-1) were used to assess the fibroblast-mediated contraction of floating gels and chemotaxis towards fibronectin. In addition, the ability of fibroblasts to release fibronectin, transforming growth factor (TGF)- $\beta 1$, fibronectin and vascular endothelial growth factor (VEGF) was assessed. 3-Nitrotyrosine significantly inhibited gel contraction $(p<0.01)$ compared with control and this inhibition was abolished by nitric oxide synthase (NOS) inhibitor. 3-Nitrotyrosine did not affect TGF- $\beta 1$ and VEGF but significantly decreased fibronectin release $(p<0.01)$ into the media. 3-Nitrotyrosine significantly inhibited chemotaxis towards fibronectin through suppression of $\alpha_{5} \beta_{1}$ integrin expression $(p<0.01)$. NOS inhibitor also reversed 3-nitrotyrosine-inhibited chemotaxis $(p<0.01)$. Finally, 3nitrotyrosine enhanced the expression of the inducible type of NOS $(p<0.01)$ and nitric oxide release $(p<0.01)$ through nuclear factor- $\mathrm{KB}$ activation. These results suggest that the free amino acid form of 3-nitrotyrosine can affect the tissue repair process by modulating nitric oxide production.
\end{abstract}

KEYWORDS: Inducible nitric oxide synthase, nitric oxide, reactive nitrogen species, remodelling

xcessively produced nitric oxide (NO) derived from the inducible type of $\mathrm{NO}$ synthase (iNOS) leads to the formation of reactive nitrogen species (RNS), including peroxynitrite and nitrogen dioxide, during inflammatory and immune processes in lung diseases [1]. These RNS are formed from $\mathrm{NO}$ and superoxide anions [2] or via the $\mathrm{H}_{2} \mathrm{O}_{2}$ /peroxidase-dependent nitrite oxidation pathway [3]. Excessive RNS cause tissue injury, lipid peroxidation and nitration of tyrosine residues [1, 4]. A metabolite generally reflecting the in vivo production of RNS is the amino acid derivative 3-nitrotyrosine. The production of 3nitrotyrosine has been observed in various inflammatory lung diseases, including chronic obstructive pulmonary disease $[5,6]$, bronchial asthma $[5,7]$, cystic fibrosis [8] and idiopathic pulmonary fibrosis [9].

3-Nitrotyrosine was thought to be a stable marker of RNS production [10]. However, recent studies have established that, in addition to serving as a "footprint" of RNS, the free amino acid form of 3nitrotyrosine itself induces cytotoxity, growth inhibition and morphological changes, and consequently alters the cellular function in cultured cells [11-13]. These studies suggest that 3nitrotyrosine may play a critical role in the tissue repair process. Indeed, its abundant production (1-120 $\mu \mathrm{M})$ has been shown under several pathological conditions, including rheumatoid arthritis [14], liver transplantation [15], septic shock [16] and amyotrophic lateral sclerosis [17]. However, whether 3-nitrotyrosine can affect the tissue repair response remains unknown.

Inflammatory processes are frequently accompanied by alterations in the tissue structure. Such alterations may result from tissue damage due to active proteases or toxic moieties released by inflammatory cells. In addition, mediators released at inflammatory sites are capable of directly altering the cell function, leading to tissue repair and remodelling. In human lung fibroblasts, recent studies showed that cytokine stimulation is associated with iNOS gene expression [18]. Gaseous NO can also stimulate iNOS expression [19]. Furthermore, we have shown
AFFILIATIONS

*Third Dept of Internal Medicine, Wakayama Medical University School of Medicine, Wakayama, Japan. \#Pulmonary Medicine, Nebraska Medical Center, Omaha, NE, USA.

\section{CORRESPONDENCE}

H. Sugiura

Third Dept of Internal Medicine

Wakayama Medical University School

of Medicine

811-1 Kimiidera

Wakayama

Wakayama 641-0012

Japan

E-mail: sugiura@wakayama-

med.ac.jp

Received:

Dec 252008

Accepted after revision:

April 182009

First published online:

May 142009 
that cytokine-induced NO inhibited collagen gel contraction, which is a novel tissue repair model [20]. These studies suggest that iNOS expression can be stimulated in human lung fibroblasts and NO derived from iNOS may affect the tissue repair process. On the basis of these observations, we hypothesised that the free amino acid form of 3-nitrotyrosine can modulate iNOS expression in human lung fibroblasts and affect the tissue repair process.

The present study, therefore, was designed first to determine whether 3-nitrotyrosine could affect tissue remodelling through an effect on the human fetal lung fibroblast (HFL-1)mediated contraction of collagen gels and chemotaxis towards chemoattractant. Next, we assessed whether 3-nitrotyrosine can modulate fibroblast release of fibronectin, transforming growth factor (TGF)- $\beta 1$ and vascular endothelial growth factor (VEGF), which are thought to be critical mediators of tissue remodelling. Finally, we determined whether the effects of 3nitrotyrosine were mediated through excessive production of NO derived from iNOS.

\section{MATERIALS AND METHODS}

\section{Materials}

Native type I collagen (rat tail tendon collagen (RTTC)) was extracted from rat tail tendons by a previously published method [21]. Briefly, tendons were excised from rat tails, and the tendon sheath and other connective tissues were removed carefully. Repeated washing with Tris-buffered saline $(0.9 \%$ $\mathrm{NaCl}$ and $10 \mathrm{mM}$ Tris, $\mathrm{pH}$ 7.5) was followed by dehydration and sterilisation with 50\%, 75\%, 95\% and pure ethanol. Type I collagen was then extracted in $6 \mathrm{mM}$ hydrochloric acid at $4^{\circ} \mathrm{C}$. The collagen concentration was determined by weighing a lyophilised aliquot from each lot of collagen solution. Sodium dodecylsulfate-polyacrylamide gel electrophoresis (SDS-PAGE) consistently demonstrated no detectable proteins other than type I collagen.

Commercially available reagents were obtained as follows: 3nitrotyrosine, indomethacin, $N^{\mathrm{G}}$-mono-methyl-L-arginine acetate salt (L-NMMA), sodium nitroprusside (SNP), L- $N^{6}$-(1-iminoethyl) lysine (L-NIL), 3,3',5,5'-tetramethylebenzidine, lipopolysaccharide (LPS) and 3-(4,5-dimethylthiazol-2-yl)-2,5-diphenyltetrazolium bromide (MTT) were from Sigma (St Louis, MO, USA); caffeic acid phenethyl ester (CAPE) and nuclear factor (NF)- $\kappa B$ inhibitors were from Calbiochem (La Jolla, CA, USA); Dulbecco's modified Eagle medium (DMEM) and fetal calf serum (FCS) were from Invitrogen Life Technologies (Grand Island, NY, USA).

\section{Cell culture}

HFL-1 cells were obtained from the American Type Culture Collection (Rockville, MD, USA). The cells were cultured on tissue culture dishes (Falcon; Becton-Dickinson Labware, Lincoln Park, NJ, USA) with DMEM supplemented with $10 \%$ FCS, $100 \mu \mathrm{g} \cdot \mathrm{mL}^{-1}$ penicillin, $250 \mu \mathrm{g} \cdot \mathrm{mL}^{-1}$ streptomycin and $2.5 \mu \mathrm{g} \cdot \mathrm{mL}^{-1}$ fungizone. Cells were cultured at $37^{\circ} \mathrm{C}$ in a humidified atmosphere of $5 \% \mathrm{CO}_{2}$ and passaged every 4 5 days at a 1:4 ratio. HFL-1 cells were used between the 14th and 18 th passages. At $30 \%$ confluence, cells were treated with varying concentrations of 3-nitrotyrosine in DMEM containing $10 \%$ FCS for $48 \mathrm{~h}$. Cells were then harvested for later assay.

\section{Collagen gel contraction assay}

Collagen gels were prepared as described previously [22, 23]. Briefly, RTTC, distilled water and $4 \times$ concentrated DMEM were combined so that the final mixture resulted in $0.75 \mathrm{mg} \cdot \mathrm{mL}^{-1}$ collagen, with a physiological ionic strength of $1 \times$ DMEM and a $\mathrm{pH}$ of 7.4. Cells were plated in 100-mm dishes in DMEM containing $10 \%$ FCS and treated with or without various concentrations of 3-nitrotyrosine for $48 \mathrm{~h}$. To investigate the effect of the NOS inhibitors on fibroblast-mediated gel contraction, L-NMMA or L-NIL was added to the culture media in monolayers with or without varying concentrations of 3nitrotyrosine. The cells were trypsinised (trypsin-EDTA: $0.05 \%$ trypsin, $0.53 \mathrm{mM}$ EDTA-4Na; GIBCO, Invitrogen) and suspended in serum-free DMEM. The cells were then mixed with the neutralised collagen solution so that the final cell density in the collagen solution was $3 \times 10^{5}$ cells $\cdot \mathrm{mL}^{-1}$ and the final concentration of collagen was $0.75 \mathrm{mg} \cdot \mathrm{mL}^{-1}$. Aliquots $\left(0.5 \mathrm{~mL} \cdot \mathrm{well}^{-1}\right)$ of the mixture of cells in collagen were cast into each well of 24-well tissue culture plates (Falcon) and allowed to gel. After gelation was completed, normally within $20 \mathrm{~min}$ at room temperature, the gels were gently released from the 24-well tissue culture plates and transferred into $60-\mathrm{mm}$ tissue culture dishes (three gels in each dish) that contained $5 \mathrm{~mL}$ of freshly prepared serum-free DMEM with or without various concentrations of 3-nitrotyrosine. The gels were then incubated at $37^{\circ} \mathrm{C}$ in a $5 \% \mathrm{CO}_{2}$ atmosphere for 3 days. To investigate the effect of $\mathrm{L}-$ NMMA or L-NIL on fibroblast-mediated gel contraction, LNMMA or L-NIL was added to the culture media after the gels were released. Gel contraction was quantified daily using an Optomax V image analyser (Optomax, Burlington, MA, USA). Data were expressed as percentages of the original gel size.

\section{Measurement of fibronectin, TGF- $\beta 1$ and VEGF by ELISA}

Fibronectin, TGF- $\beta 1$ and VEGF in the media of the monolayer culture were determined by ELISA according to a previous report [23].

\section{Chemotaxis assay}

Cell migration was assessed using the Boyden blindwell chamber (Neuroprobe Inc., Gaithersburg, MD, USA) as previously described $[23,24]$. Briefly, $26 \mu \mathrm{L}$ of serum-free DMEM containing human fibronectin $\left(20 \mu \mathrm{g} \cdot \mathrm{mL}^{-1}\right)$ was placed into the bottom wells. Polycarbonate membranes with $8-\mu \mathrm{m}$ pores (Neuroprobe Inc.), which were pre-coated with $5 \mu \mathrm{g} \cdot \mathrm{mL}^{-1}$ gelatin in $0.1 \%$ acetic acid, were used. The cells were pretreated with or without various concentrations of 3-nitrotyrosine for $48 \mathrm{~h}$. To investigate the role of NOS, L-NMMA was added to the culture media with or without 3-nitrotyrosine. The cells grown to $75 \%$ confluence were rinsed, re-fed with serum-free DMEM and treated with various concentrations of 3-nitrotyrosine at $37^{\circ} \mathrm{C}$ in a humidified atmosphere of $5 \% \mathrm{CO}_{2}$. The cells were trypsinised and suspended in serum-free DMEM at a density of $1 \times 10^{6}$ cells $\cdot \mathrm{mL}^{-1} .50 \mathrm{~mL}$ of cell suspension treated with various concentrations of 3nitrotyrosine in the presence or absence of L-NMMA were then added into each top well. The cells were allowed to migrate at $37^{\circ} \mathrm{C}$ in a $5 \% \mathrm{CO}_{2}$ atmosphere for $6 \mathrm{~h}$. Cells that had not migrated were scraped off the upper surface of the membrane and the membranes were air dried. The cells were then stained with PROTOCOL (Fisher Scientific, Swedesboro, NJ, USA) and mounted on a glass microscope slide. Chemotaxis was assessed by counting the numbers of cells in five high-power fields. 
Wells with serum-free DMEM were used as negative controls and those with chemoattractant alone were used as positive controls.

\section{Western blotting}

To investigate the effects of NF- $\mathrm{KB}$ activation on iNOS expression, cells were treated with or without various concentrations of CAPE $30 \mathrm{~min}$ prior to treatment with 3nitrotyrosine. After treatment with various concentrations of 3nitrotyrosine for $48 \mathrm{~h}$ in a monolayer culture, cells were washed with $4{ }^{\circ} \mathrm{C}$ PBS and homogenised in cell lysis buffer (35 mM Tris-HCl, pH 7.4, 0.4 mM EGTA, 10 mM MgCl $2,1 \mu \mathrm{M}$ phenylmethylsulfonyl fluoride, $100 \mu \mathrm{g} \cdot \mathrm{mL}^{-1}$ aprotinin and $1 \mu \mathrm{g} \cdot \mathrm{mL}^{-1}$ leupeptin). Samples were solubilised in SDS-PAGE sample buffer. To investigate NF- $\kappa B$ translocation into the nucleus, cells were seeded in $60-\mathrm{mm}$ dishes at a density of $1 \times 10^{5}$ cells $\cdot \mathrm{mL}^{-1}$. At $90 \%$ confluence, the cells were treated with $10^{-4} \mathrm{M}$ 3-nitrotyrosine. The cells were harvested at various time points. To obtain the nuclear and cytosolic fractions, a nuclear extraction kit (Active Motif, Carlsbad, CA, USA) was used according to the manufacturer's instructions. Equal amounts of protein were loaded and separated by electrophoresis on $12.5 \%$ SDS-PAGE gels. After electrophoresis, the separated proteins were transferred to a polyvinylidene difluoride membrane (Bio-Rad Laboratories, Hercules, CA, USA). Primary polyclonal antibodies against human iNOS (1:100 dilution; Santa Cruz Biotechnology, Inc., Santa Cruz, CA, USA) or $\alpha_{5} \beta_{1}$ integrin (1:1,000 dilution; Chemicon International, Inc., Temecula, CA, USA), or mouse monoclonal anti-NF- $\mathrm{B}$ p65 antibody (1:200 dilution; Santa Cruz Biotechnology, Inc.) were used for detection. Bound antibodies were visualised using appropriate peroxidase-conjugated secondary antibodies and enhanced chemiluminescence (Amersham Biosciences, Little Chalfont, UK) with a Typhoon Scanner (Amersham Biosciences). The intensity of the detected band was quantified by NIH image.

\section{Quantitative PCR}

Fibroblasts were treated with or without 3-nitrotyrosine and were harvested at $12 \mathrm{~h}$. Total RNA was eluted using an RNeasy mini kit (Qiagen Sciences, Valencia, CA, USA). cDNA was generated using reverse transcriptase. The primers for iNOS were designed as follows: forward CCCCACGCTGCATTGG; reverse CACGTGTCTGCAGATGTGTTCA. Gene expression was measured using assays on the above probe and primers and reactions were analysed by using the ABI 7000 Taqman ${ }^{\circledR}$ system (Applied Biosystems, Foster City, CA, USA).

\section{Measurement of nitrite/nitrate}

To evaluate nitrite/nitrate production in the monolayer culture, cells were seeded in 6-well tissue plates at a cell density of $1 \times 10^{5}$ cells $\cdot \mathrm{mL}^{-1}$. The cells were treated with or without varying concentrations of 3-nitrotyrosine for $48 \mathrm{~h}$ and the supernatant was harvested. The concentration of nitrite/ nitrate was determined by a Nitric oxide assay kit (Assay Designs, Inc., Ann Arbor, MI, USA).

\section{MTT assay}

For monitoring cell viability, the 3-nitrotyrosine-treated cells were incubated with MTT solution at a final concentration of $1 \mathrm{mg} \cdot \mathrm{mL}^{-1}$ for $4 \mathrm{~h}$ at $37^{\circ} \mathrm{C}$. After incubation, dimethyl sulfoxide was added into each well. The absorbance of each sample at $570 \mathrm{~nm}$ was determined by a spectrophotometer using a reference wavelength of $630 \mathrm{~nm}$.

\section{Statistical analysis}

Data were expressed as mean \pm SEM. Multiple comparisons of experimental values among the groups were evaluated by oneway ANOVA followed by Bonferroni's post hoc test to test for multiple comparisons and the Mann-Whitney U-test for single comparisons. Probability values of $<0.05$ were considered significant.

\section{RESULTS}

At first, we examined the effect of 3-nitrotyrosine on the cell viability. 3-Nitrotyrosine did not affect the cell viability in either the collagen gel culture condition or the chemotaxis condition (see supplementary fig. 1).

To investigate the 3-nitrotyrosine modulation of collagen gels, cells cast in collagen gels were floated in media with various concentrations of 3-nitrotyrosine. 3-Nitrotyrosine significantly inhibited the gel contraction compared with control in a concentration-dependent manner (at $10^{-4} \mathrm{M}$, gel size was $81.0 \pm 0.4 \%$ versus $65.9 \pm 0.1 \%$ of initial size on day $3 ; p<0.01$; fig. 1). The NOS inhibitor L-NMMA $\left(10^{-4} \mathrm{M}\right)$ completely abolished the inhibitory effect of 3-nitrotyrosine on gel contraction compared with the 3-nitrotyrosine-treated group (on day 3, gel size was $71.5 \pm 0.7 \%$ versus $88.6 \pm 1.2 \%$ of initial size; $\mathrm{p}<0.01$; fig. 2a), while the cyclooxygenase inhibitor indomethacin $\left(2 \times 10^{-6} \mathrm{M}\right)$ had no effect on the 3-nitrotyrosine-mediated inhibition of gel contraction (on day 3 , gel size was $86.4 \pm 1.0 \%$ versus $88.6 \pm 1.2 \%$ of initial size; fig. $2 \mathrm{~b}$ ). To investigate whether iNOS was related to the L-NMMA-mediated effect, the effects of a specific iNOS inhibitor L-NIL on the 3-nitrotyrosine-mediated inhibition of gel contraction was assessed. As shown in figure 3, L-NIL significantly reversed the 3-nitrotyrosine-mediated inhibition of gel contraction in a concentration-dependent manner (at $10^{-5}-10^{-4} \mathrm{M} ; \mathrm{p}<0.01$ ). To investigate the role of iNOS in the tissue repair, we treated the cells with LPS to stimulate the iNOS expression. LPS significantly augmented iNOS expression $(\mathrm{p}<0.01$; supplementary fig. $2 \mathrm{a})$. LPS significantly attenuated fibronectin release in the media compared with control $\left(4,217 \pm 464\right.$ versus $8,131 \pm 585 \mathrm{ng} \cdot$ culture $^{-1} ; \mathrm{p}<0.01$; supplementary fig. 2b). L-NIL significantly restored the LPS-attenuated fibronectin release $\left(6,750 \pm 391\right.$ versus $4,217 \pm 464 \mathrm{ng} \cdot$ culture $^{-1}$; $\mathrm{p}<0.01$; supplementary fig. $2 \mathrm{~b}$ ).

It is known that fibronectin and TGF- $\beta 1$ are involved in tissue repair and are able to enhance collagen gel contraction by human lung fibroblasts. VEGF is believed to contribute to vascular cell proliferation and may be a mediator of tissue repair and remodelling. To determine whether 3-nitrotyrosine could contribute to the release of these mediators, the release of these three mediators in the monolayer culture was evaluated. 3-Nitrotyrosine $\left(10^{-5}-10^{-4} \mathrm{M}\right)$ significantly decreased fibronectin release in the monolayer culture $(p<0.01$; fig. $4 a)$, while it did not affect the release of TGF- $\beta 1$ (fig. $4 b$ ) and VEGF (fig. 4c) in the monolayer culture.

Because fibroblast migration from neighbouring connective tissue into sites of inflammation plays an important role in tissue repair in response to injury, we assessed the effect of 

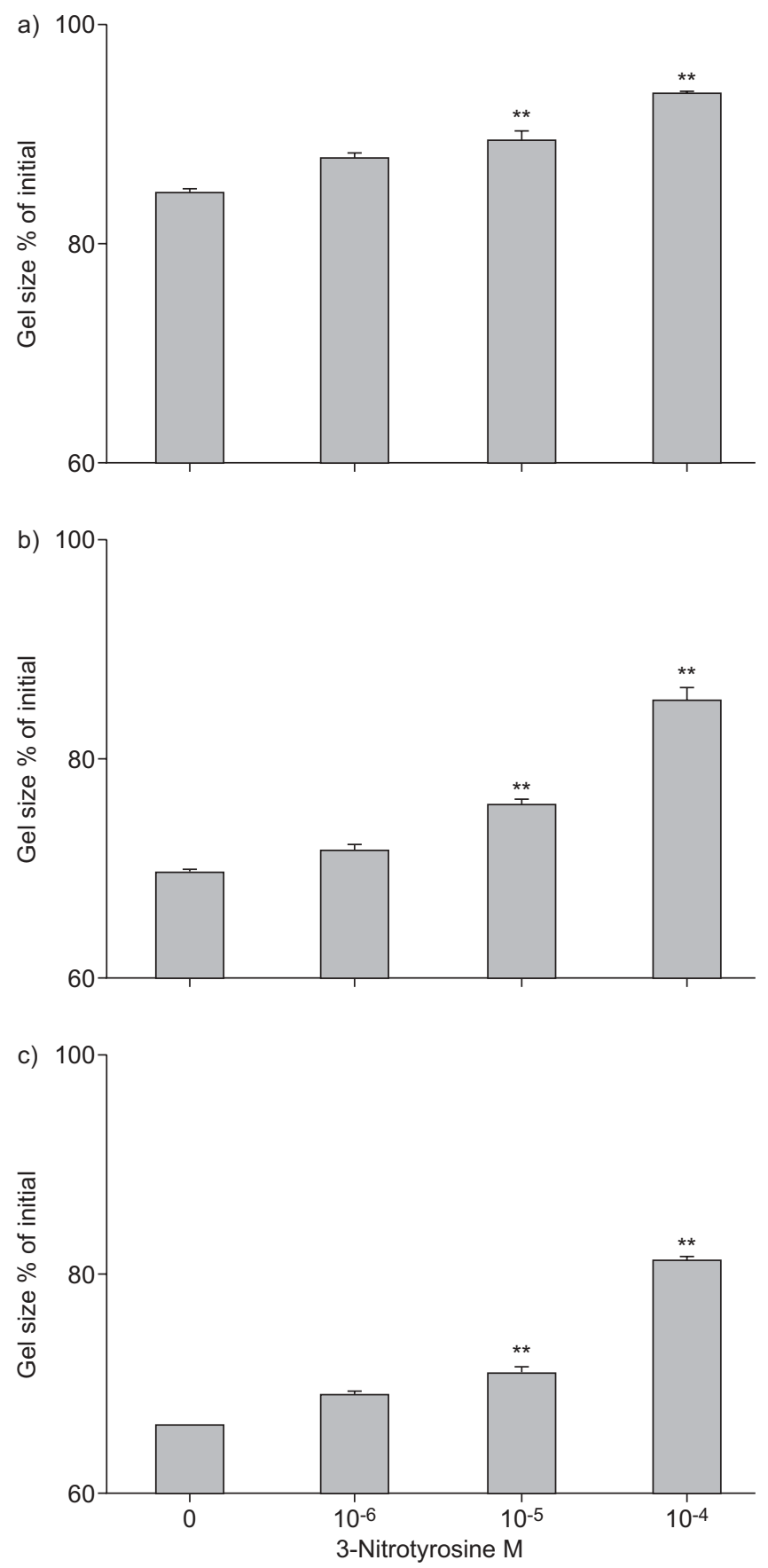

FIGURE 1. Effect of 3-nitrotyrsoine on collagen gel contraction by human fetal lung fibroblasts. Gel size was measured on a) day 1, b) day 2 and c) day 3. All values are mean \pm SEM for four separate experiments, each performed in triplicate. **: $p<0.01$ compared with control.

3-nitrotyrosine on HFL-1 chemotaxis. Using fibronectin $\left(20 \mu \mathrm{g} \cdot \mathrm{mL}^{-1}\right)$ as the chemoattractant, 3-nitrotyrosine significantly inhibited fibroblast chemotaxis compared with control in a concentration-dependent manner (at $10^{-4} \mathrm{M}, 248 \pm 24$ cells in five high power fields (HPF) versus $95.0 \pm 14$ cells in five HPF; $p<0.01$; fig. 5a). The NOS inhibitor L-NMMA $\left(10^{-4} \mathrm{M}\right)$ completely abolished the 3-nitrotyrosine-mediated inhibition of chemotaxis towards fibronectin ( $p<0.01$; fig. 5a). We also
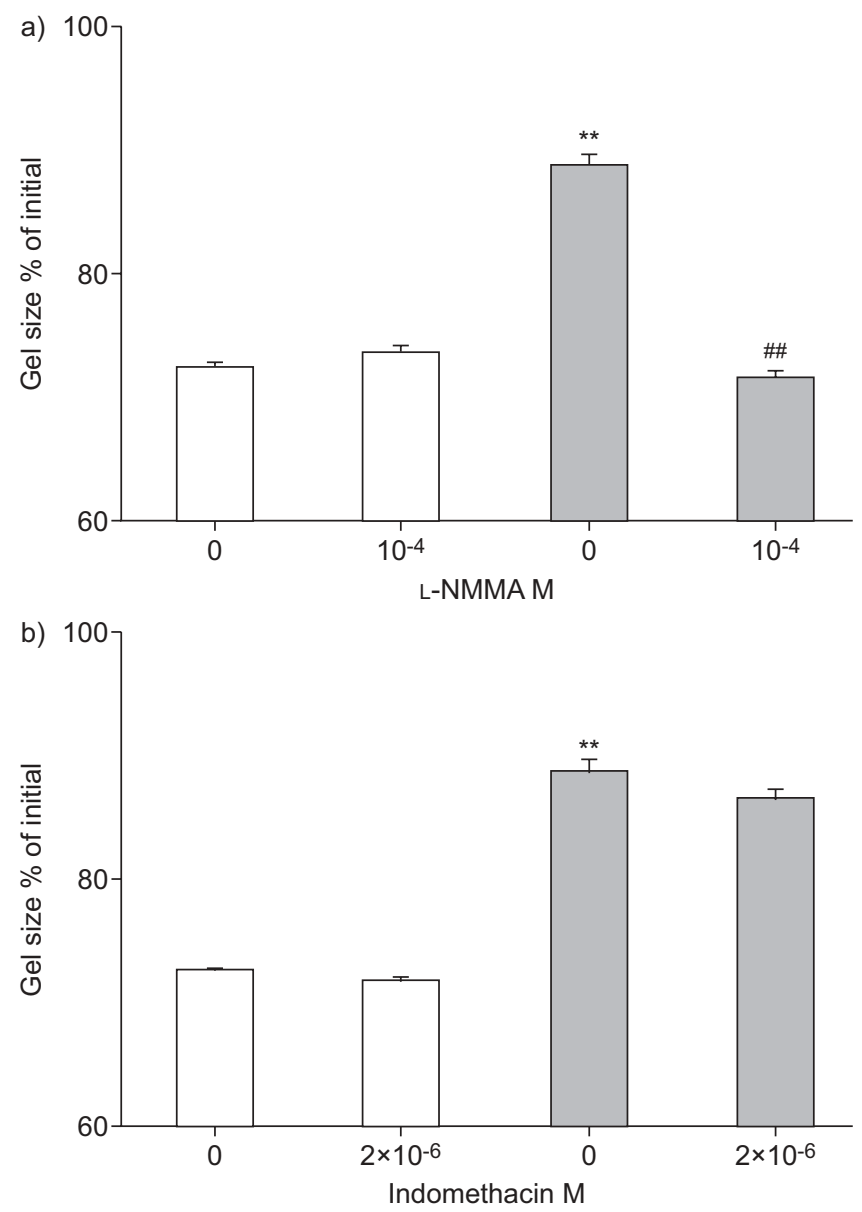

FIGURE 2. Effect of $N^{G}$-mono-methyl-L-arginine acetate salt (L-NMMA) and indomethacin on 3-nitrotyrosine-inhibited collagen gel contraction by human fetal lung fibroblasts. Fibroblasts were cast into collagen gels and maintained in floating culture in medium with ( $\square$ ) or without $(\square)$ 3-nitrotyrosine at $10^{-4} \mathrm{M}$ in the presence or absence of a) the nitric oxide synthase inhibitor L-NMMA or b) the cyclooxygenase inhibitor indomethacin. All values are mean \pm SEM for four separate

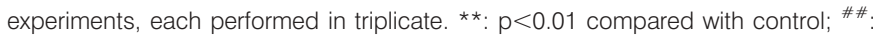
$p<0.01$ compared with 3-nitrotyrosine-treated group.

investigated the effect of NO on fibroblast-mediated chemotaxis. The NO donor SNP inhibited the chemotaxis in a concentration-dependent manner (at $10^{-3} \mathrm{M}, 223 \pm 14$ cells in five HPF versus $108 \pm 9.8$ cells in five HPF; $\mathrm{p}<0.01$; fig. $5 \mathrm{~b}$ ). To explore the possible mechanism of inhibition of chemotaxis by 3-nitrotyrosine, we investigated the effect of nitrotyrosine on the expression of $\alpha_{5} \beta_{1}$ integrin, which is a receptor for fibronectin. As shown in figure $5 \mathrm{c}, 10^{-4} \mathrm{M}$ 3-nitrotyrosine decreased the expression of $\alpha_{5} \beta_{1}$ integrin (both $\mathrm{p}<0.05$ ).

To clarify which mechanisms are related to the 3-nitrotyrosineaugmented iNOS expression, we investigated the effect of 3nitrotyrosine on NF- $\mathrm{KB}$ activation, which is thought to be the most important pathway in the regulation of iNOS expression. Fibroblasts were incubated with 3-nitrotyrosine and examined for the translocation of NF- $\mathrm{kB}$ p65 into the nucleus. There was no significant change in the translocation of NF- $\kappa B$ into the nucleus from 0 to $120 \mathrm{~min}$ without 3-nitrotyrosine treatment (e.g. at $0 \mathrm{~min}$ versus $60 \mathrm{~min}, 1.00 \pm 0.0$ versus $1.04 \pm 0.15$ relative intensity of 


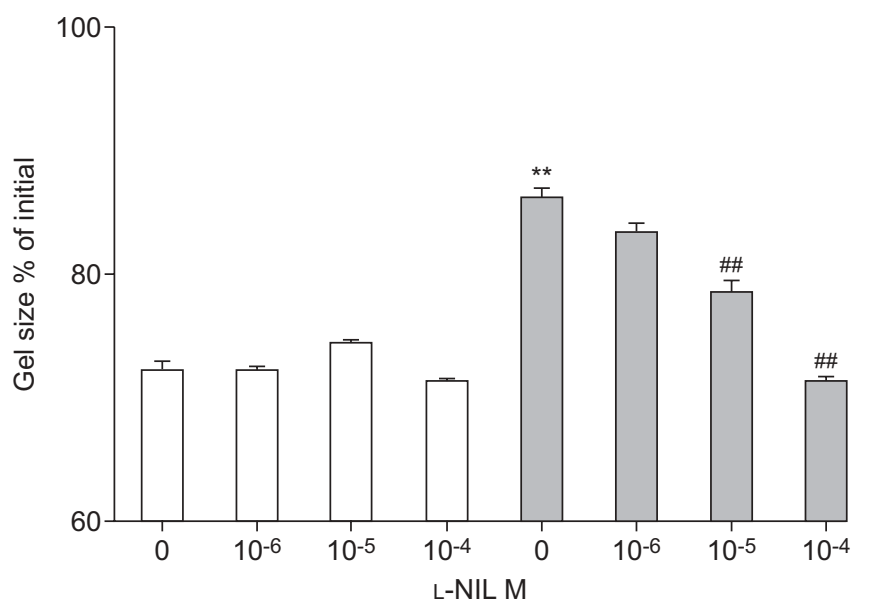

FIGURE 3. Effect of various concentrations of L- $N^{6}$-(1-iminoethyl)lysine (L-NIL) on 3-nitrotyrosine-mediated inhibition of gel contraction. Fibroblasts were maintained in floating culture in medium with ( $\square$ ) or without ( $\square$ ) 3-nitrotyrosine at $10^{-4} \mathrm{M}$ in the presence or absence of varying concentrations of L-NIL. All values are mean \pm SEM for four separate experiments, each performed in triplicate. ${ }^{* *}: p<0.01$ compared with control; \#\#: $p<0.01$ compared with vehicle-treated 3-nitrotyrosineexposed group.

$\mathrm{NF}-\kappa \mathrm{B} /$ lamin $\mathrm{A} / \mathrm{C}$ ), whereas $10^{-4} \mathrm{M} 3$-nitrotyrosine significantly enhanced the translocation of NF- $\mathrm{KB}$ into the nucleus at $60 \mathrm{~min}$ as shown in figure $6 a(p<0.01)$. Furthermore, a novel NF- $\kappa B$ inhibitor, CAPE, significantly suppressed the 3-nitrotyrosineaugmented iNOS expression (at $0.3-1.0 \mu \mathrm{g} \cdot \mathrm{mL}^{-1} \mathrm{CAPE} ; \mathrm{p}<0.01$; fig. $6 \mathrm{~b}$ ). These results suggest that 3-nitrotyrosine stimulated NF- $\kappa \mathrm{B}$ activation and augmented iNOS expression through $\mathrm{NF}-\kappa \mathrm{B}$ activation.

To clarify whether 3-nitrotyrosine augments the expression of iNOS, fibroblasts were incubated with 3-nitrotyrosine and examined for the expression of iNOS mRNA and protein. As shown in figure $7 \mathrm{a}$ and $\mathrm{b}, 10^{-4} \mathrm{M}$ 3-nitrotyrosine significantly enhanced the expression of iNOS mRNA and protein $(\mathrm{p}<0.01)$. Furthermore, NO release in the media of the HFL-1 cell culture was investigated. 3-Nitrotyrosine significantly enhanced the release of $\mathrm{NO}$ in the media of the HFL-1 culture in a concentration-dependent manner (at $10^{-4} \mathrm{M} ; \mathrm{p}<0.01$; fig. 7c).

Because 3-nitrotyrosine is incorporated into $\alpha$-tubulin in various types of cells and changes the cellular function, we investigated the incorporation of 3-nitrotyrosine into $\alpha$-tubulin by western blotting. 3-Nitrotyrosine was not incorporated into $\alpha$-tubulin in HFL-1 cells assessed by western blotting (supplementary fig. 3).

\section{DISCUSSION}

The present study demonstrated that the free amino acid form of 3-nitrotyrosine inhibits the fibroblast-mediated contraction of three-dimensional collagen gels and fibroblast chemotaxis towards fibronectin. 3-Nitrotyrosine also significantly decreased fibronectin release into the supernatant of the monolayer cultures. The NOS inhibitors L-NMMA and L-NIL recovered the 3-nitrotyrosine-inhibited gel contraction, mediator production and chemotaxis towards fibronectin. Furthermore, 3nitrotyrosine enhanced the expression of iNOS protein through $\mathrm{NF}-\kappa \mathrm{B}$ activation and NO production. These results suggest that
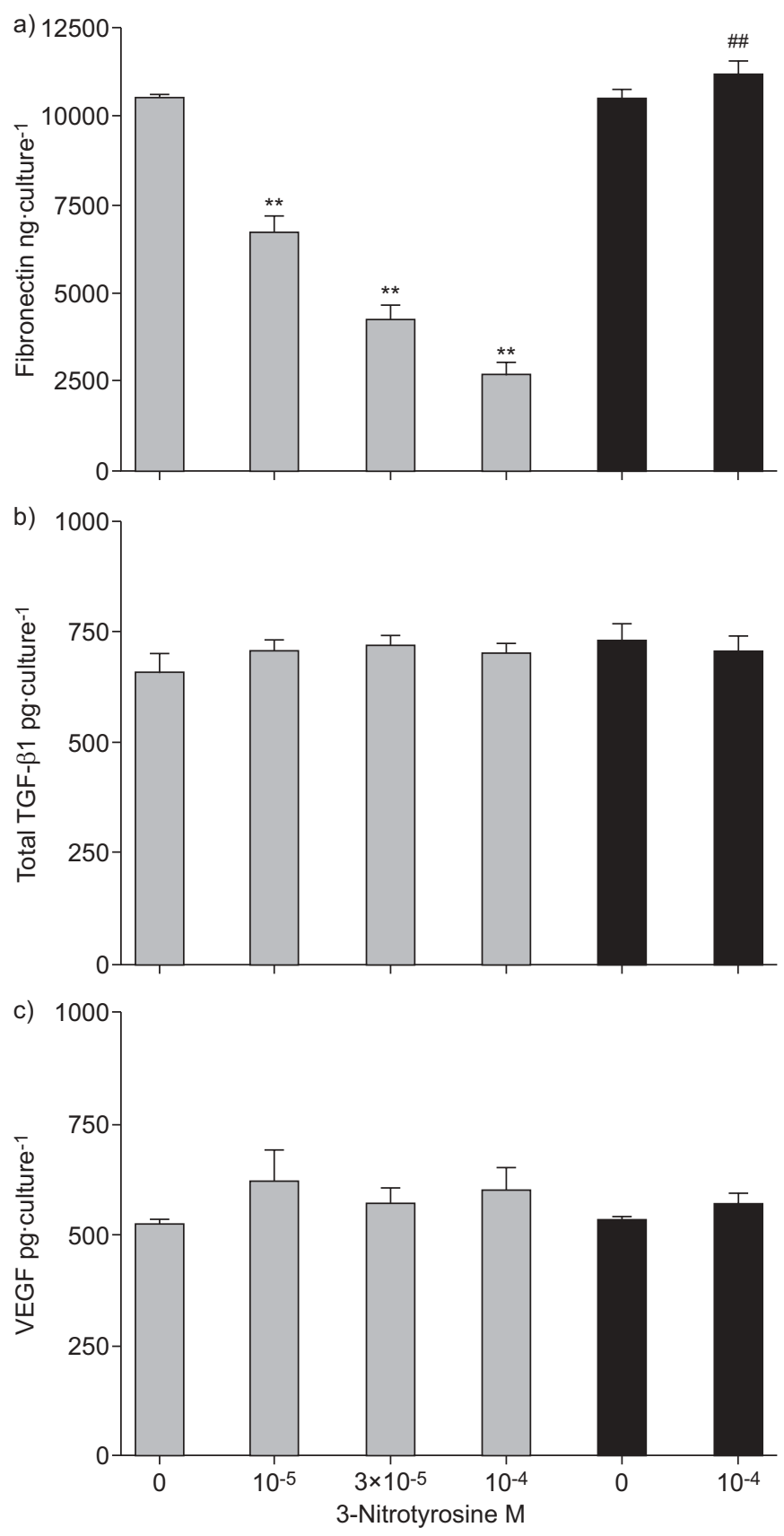

FIGURE 4. Effect of 3-nitrotyrosine on a) fibronectin, b) transforming growth factor (TGF)- $\beta 1$ and c) vascular endothelial growth factor (VEGF) release. The effect of $N^{G}$-mono-methyl-L-arginine acetate salt at $10^{-4} \mathrm{M}$ was also tested ( $\mathbf{\square}$ ). Media were assayed by ELISA. All values are mean \pm SEM for four separate experiments, each performed in duplicate. **: $p<0.01$ compared with control; *\#: $p<0.01$ compared with vehicle-treated 3-nitrotyrosine-exposed $\left(10^{-4} \mathrm{M}\right)$ group.

3-nitrotyrosine can affect fibroblast-mediated repair processes and that the mechanism of this effect depends on the generation of $\mathrm{NO}$.

3-Nitrotyrosine is a marker of nitration of the free amino acid form of tyrosine or tyrosine residues of proteins [4]. Recently, it has been reported that the free amino acid form of 3nitrotyrosine is not only a marker of RNS, but also induces 


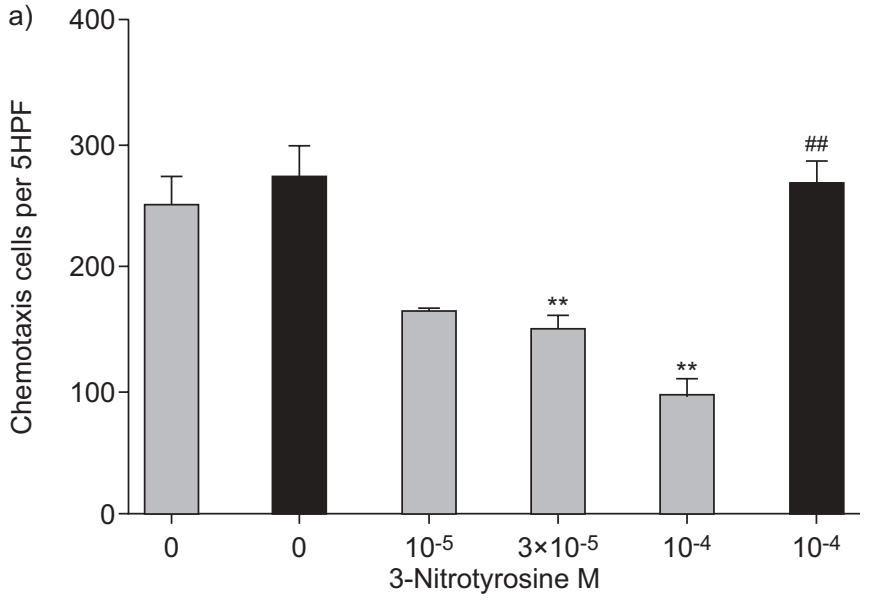

c)

3-Nitrotyrosine M 0

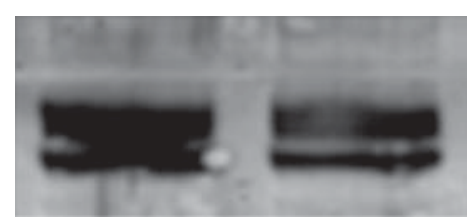

$\beta_{1}$-integrin

$\beta$-actin

d) 20
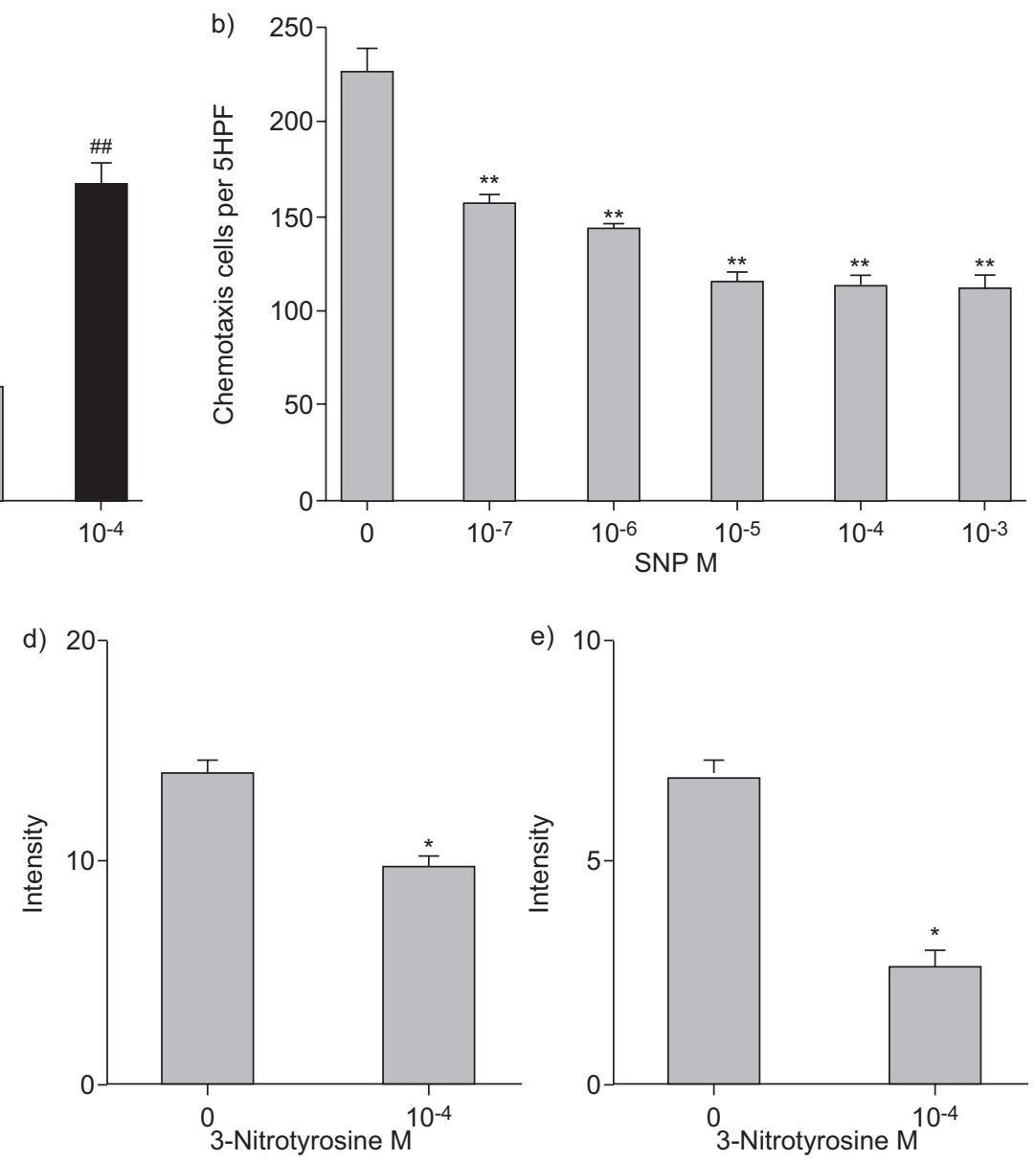

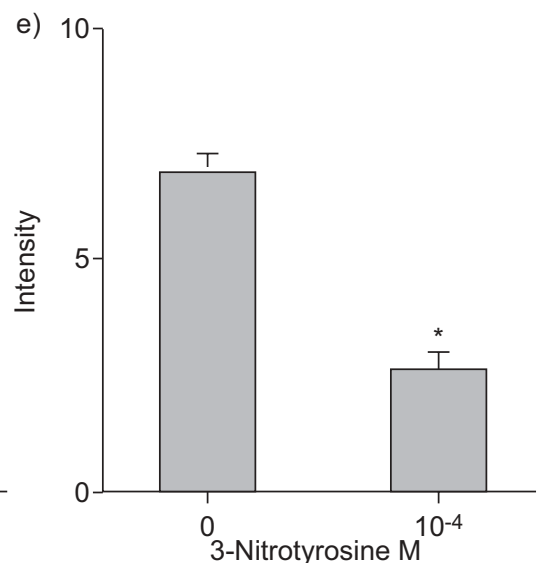

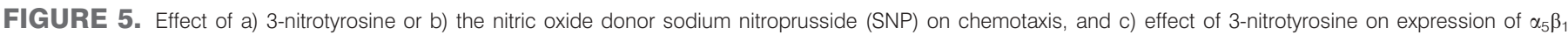

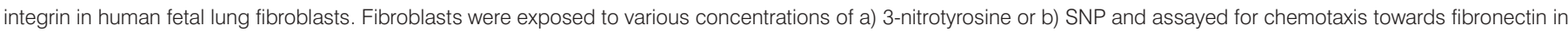

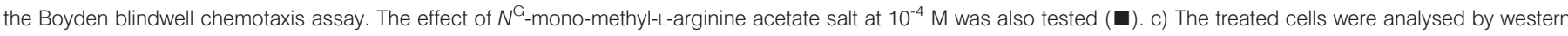

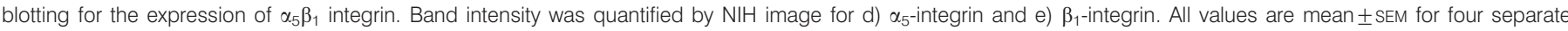
experiments. ${ }^{*}: \mathrm{p}<0.05$ compared with control; **: $\mathrm{p}<0.01$ compared with control; ${ }^{\# \#}: \mathrm{p}<0.01$ compared with $3-$ nitrotyrosine-treated (10-4 $\mathrm{M}$ ) group.

cytotoxity, growth inhibition and morphological changes, and consequently alters the cellular function in cultured cells [1113]. Our findings demonstrate that 3-nitrotyrosine leads to the decreased release of fibronectin that drives fibroblast-mediated repair responses. Fibronectin, a multifunctional glycoprotein involved in tissue remodelling, is a chemoattractant for lung fibroblasts [25] and can be released in increased amounts from fibroblasts [25] and epithelial cells [26, 27] in response to a variety of cytokines. According to a previous study, both the cellular type and plasma type of fibronectin enhanced collagen gel contraction [28]. In the present study, 3-nitrotyrosine reduced fibronectin production and NOS inhibitor reversed the 3-nitrotyrosine-reduced fibronectin production, suggesting that $\mathrm{NO}$ can reduce fibronectin production in human lung fibroblast.

RNS have a variety of biological effects, including tissue injury, lipid peroxidation and nitration of protein tyrosine residues. We have shown that RNS are excessively produced in the airways of asthmatics [5] and that endogenously produced RNS cause airway inflammation in late allergic response model [29]. Recently, we have shown that peroxynitrite, one of the RNS, stimulates fibroblasts. Peroxynitrite stimulates the differentiation of fibroblasts into myofibroblasts and extracellular matrix protein production in vitro $[23,30]$, suggesting that RNS induce fibroblast-mediated profibrotic responses. In the current study, free 3-nitrotyrosine caused the inhibition of tissue remodelling in vitro. 3-Nitrotyrosine produced by RNS may counteract the RNS-mediated profibrotic responses.

$\mathrm{NO}$ is synthesised in a variety of cell types by the enzyme NOS, which exists in constitutive and inducible isoforms [29]. It has been reported that inflammatory cytokines can induce iNOS in human pulmonary fibroblasts [18]. In the current study, 3-nitrotyrosine induced iNOS protein through NF- $\mathrm{B}$ activation in human lung fibroblasts. 3-Nitrotyrosine can also stimulate NO production in fibroblasts. Furthermore, the NOS inhibitor L-NMMA and the iNOS inhibitor L-NIL diminished the 3-nitrotyrosine-induced inhibition of collagen gel contraction, chemotaxis and fibronectin production, suggesting that 3-nitrotyrosine might affect the tissue repair process through NO production derived from iNOS.

The regulation of fibroblast recruitment in vivo is likely to depend on both the chemotactic factors and inhibitors. 
a)

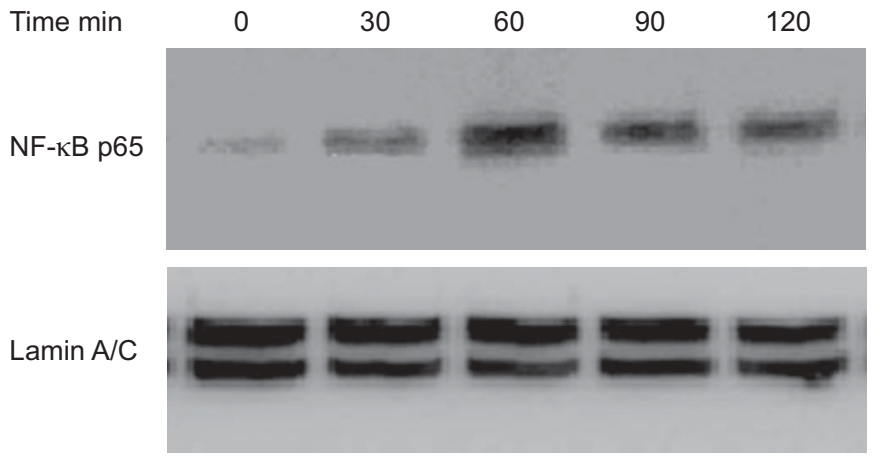

c)

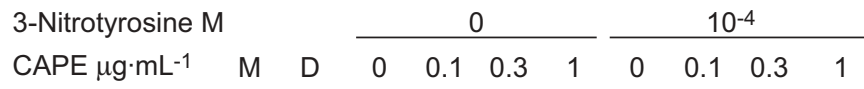
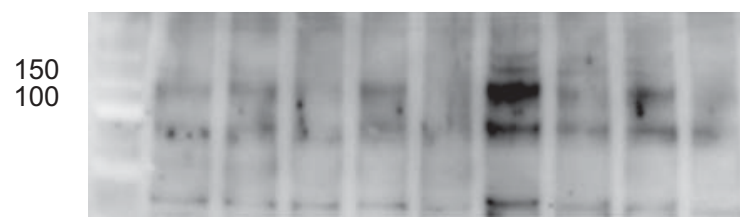

$\beta$-actin

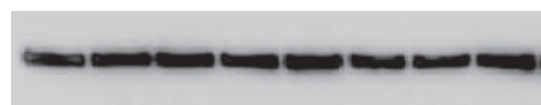

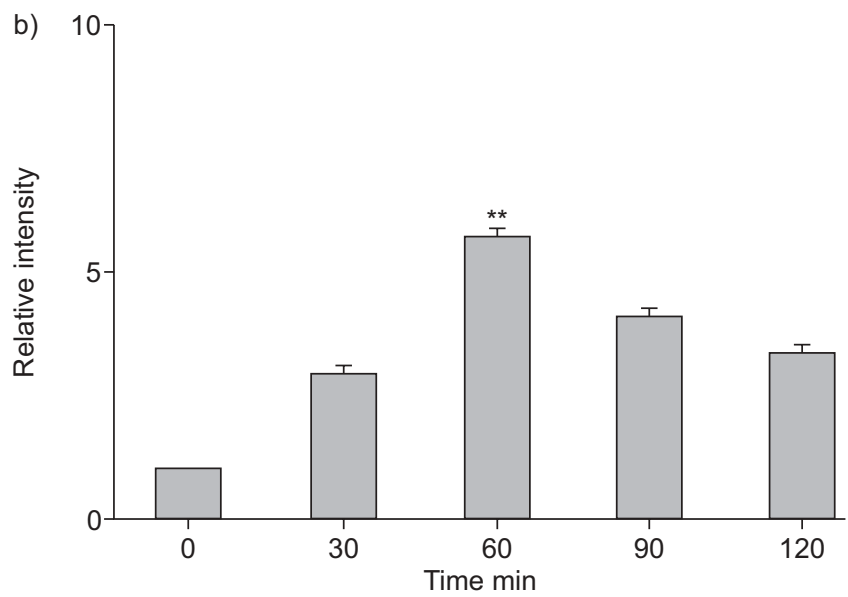

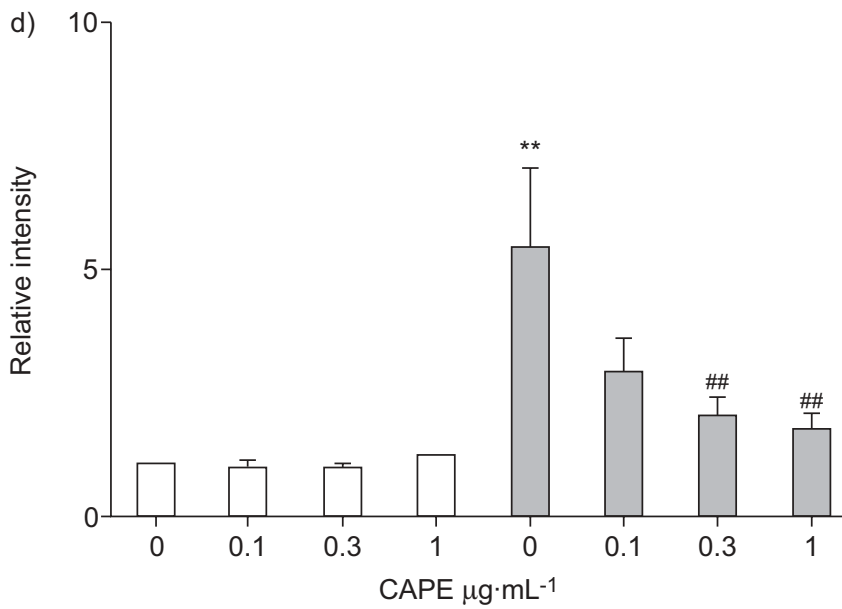

FIGURE 6. Effect of 3-nitrotyrosine on nuclear factor (NF)-kB p65 translocation into the nucleus and effect of an NF-kB inhibitor on the 3-nitrotyrosine-augmented inducible type nitric oxide synthase (iNOS) expression. a and b) Cells were treated with $10^{-4} \mathrm{M}$ 3-nitrotyrosine and harvested at 0-120 min. The amount of NF-kB p65 translocated into the nucleus was assessed by western blotting. $\mathrm{c}$ and d) Cells were pretreated with the NF-kB inhibitor, caffeic acid phenethyl ester (CAPE), followed by treatment with ( $\square$ ) or without ( $\square$ ) 3-nitrotyrosine at $10^{-4} \mathrm{M}$ for $48 \mathrm{~h}$. Cells were harvested and iNOS expression was assessed by western blotting. b and d) Band intensity was quantified by NIH image. M: molecular marker lane; D: the same amount of control protein was loaded to prevent "smiling". All values are mean \pm SEM for four separate experiments. ${ }^{* *}: p<0.01$ compared with control; ${ }^{\# \#: ~} p<0.01$ compared with vehicle-treated 3-nitrotyrosine-exposed group.

Fibronectin can augment chemotactic activity in fibroblasts [25]. The current study demonstrated that 3-nitrotyrosine inhibited chemotaxis and NOS inhibitor abolished the 3nitrotyrosine-induced inhibition of chemotaxis. Exogenously administrated NO also inhibited the fibroblast-mediated chemotaxis. Moreover, 3-nitrotyrosine can stimulate iNOS expression and NO production. Taken together, 3-nitrotyrosine inhibits chemotaxis through NO production. To explore the possible mechanism by which 3-nitrotyrosine inhibits fibroblastmediated chemotaxis towards fibronectin, we investigated the effect of 3-nitrotyrosine on the expression of $\alpha_{5} \beta_{1}$ integrin, which is a receptor for fibronectin. In the present study, we found that 3-nitrotyrosine inhibited the expression of $\alpha_{5} \beta_{1}$ integrin. Therefore, 3-nitrotyrosine may inhibit chemotaxis through the suppression of $\alpha_{5} \beta_{1}$ integrin expression.

3-Nitrotyrosine could stimulate iNOS protein expression and $\mathrm{NO}$ production in the current study. Interestingly, 3-nitrotyrosine can stimulate NF- $\kappa \mathrm{B}$ translocation into the nucleus. In general, NF- $\kappa \mathrm{B}$ activation is a key process in the regulation of iNOS expression. To our knowledge, this is the first report showing that 3-nitrotyrosine stimulates NF- $\mathrm{B}$ activation in lung fibroblasts. Although RNS are reported to stimulate NF- $\kappa B$ [30], nitrotyrosine derived from RNS may cause inflammation through $\mathrm{NF}-\kappa \mathrm{B}$.

In the current study, we attempted to examine the role of NO derived from all types of NOS in the fibroblast function. We found that NO could attenuate the fibroblast function because a nonspecific NOS inhibitor, L-NMMA, restored the 3nitrotyrosine-inhibited gel contraction (fig. 2a). Then, we found that 3-nitrotyrosine augmented iNOS expression through NF- $\mathrm{B}$ activation. In the next step, we investigated the effects of NO derived from iNOS on the fibroblast function by means of a specific iNOS inhibitor, L-NIL. As we expected, the iNOS inhibitor significantly restored the 3-nitrotyrosineinhibited gel contraction to the same degree as L-NMMA, as shown in figures $2 \mathrm{a}$ and 3 , suggesting that $\mathrm{NO}$ derived from iNOS is a key mediator in the attenuation of the fibroblast function. Although we only showed that NO derived from iNOS could inhibit the gel contraction in the present study, these findings encourage us to speculate that L-NIL also may inhibit other fibroblast functions, including mediator production, chemotaxis and $\mathrm{NO}$ release. 


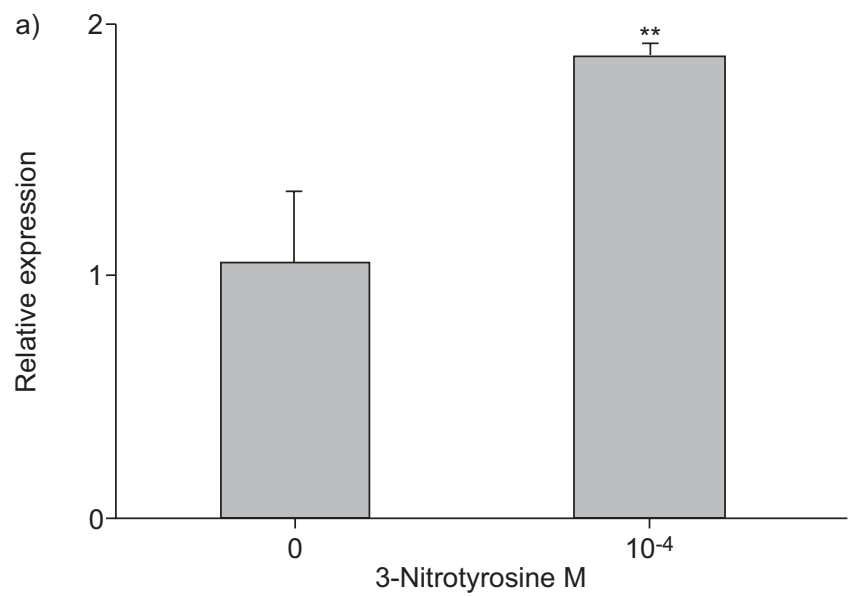

b)
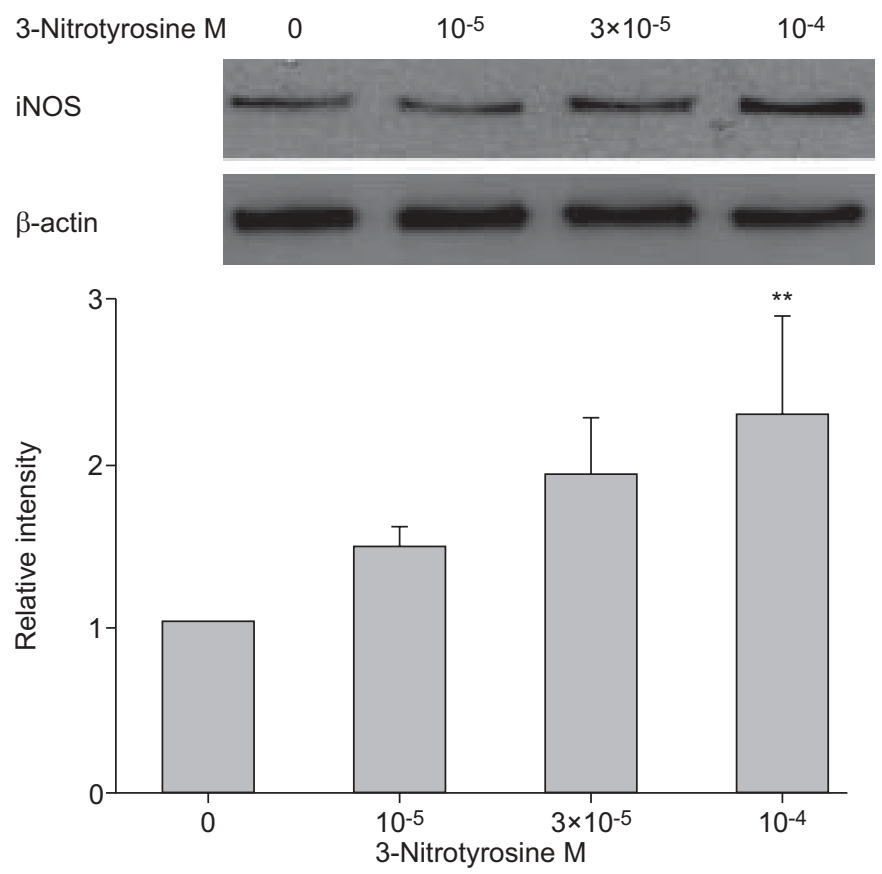

It has been reported that 3-nitrotyrosine is incorporated into $\alpha$ tubulin, induces cell morphology transformation and changes the cell function [13]. Therefore, we investigated whether 3nirotyrosine attenuates the tissue repair because of the incorporation of 3 -nitrotyrosine into $\alpha$-tubulin. To clarify this, we investigated the incorporation of 3-nitrotyrosine into $\alpha$ tubulin by western blotting. 3-Nitrotyrosine was not incorporated into the cells (supplementary fig. 3). However, we could not confirm whether the incorporation of 3-nitrotyrosine into $\alpha$-tubulin is associated with the inhibition of tissue repair observed in the current study because of the lack of a specific tubulin tyrosine ligase inhibitor. The findings that 3-nitrotyrosine is not incorporated into the cells and that NOS inhibitors inhibited the 3-nitrotyrosine-mediated inhibition of tissue repair suggest that the 3-nitrotyrosine incorporation may have had little influence on our current findings.

In summary, our data demonstrate that 3-nitrotyrsine inhibited the fibroblast-mediated contraction of three-dimensional collagen gels, chemotaxis and fibronectin production. 3-Nitrotyrosine also

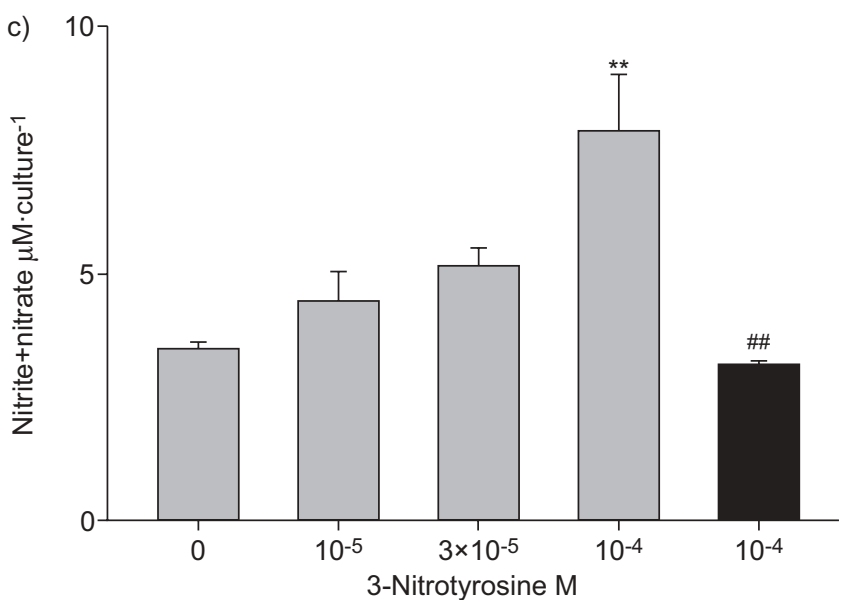

FIGURE 7. Effect of 3-nitrotyrosine on the expression of the inducible type of nitric oxide synthase (iNOS) and nitrite/nitrate production. The effects of varying concentrations of 3-nitrotyrosine on the expression of iNOS a) mRNA and b) protein were assessed by quantitative PCR and western blotting. Band intensity was quantified by $\mathrm{NIH}$ image. Expression of iNOS mRNA was calculated relative to glyceraldehyde-3-phosphate dehydrogenase. All values are mean \pm SEM for three to five separate experiments. c) Media were assayed for nitrite/nitrate production by the Griess method. The effect of $N^{G}$-mono-methyl-L-arginine acetate salt at $10^{-4} \mathrm{M}$ was also tested $(\mathbf{\square})$. All values are mean \pm SEM for four separate experiments, each performed in duplicate. ${ }^{* *}: p<0.01$ compared with control; ${ }^{\# \#}: p<0.01$ compared with vehicle-treated 3-nitrotyrosine-exposed $\left(10^{-4} \mathrm{M}\right)$ group.

augmented iNOS protein expression through NF-кB activation and the release of NO. These effects of 3-nitrotyrosine were significantly blocked by NOS inhibitor. These results suggest that the free amino acid form of 3-nitrotyrosine can affect the tissue repair process by modulating $\mathrm{NO}$ production.

\section{STATEMENT OF INTEREST}

A statement of interest for S.I. Rennard can be found at www.erj. ersjournals.com $/ \mathrm{misc} /$ statements.dtl

\section{ACKNOWLEDGEMENTS}

The authors thank B. Bell (Division of Respiratory and Infectious Diseases, Tohoku University Graduate School of Medicine, Sendai, Japan) for reading the manuscript.

\section{REFERENCES}

1 van der Vliet A, Eiserich JP, Shigenaga MK, et al. Reactive nitrogen species and tyrosine nitration in the respiratory tract: epiphenomena or a pathobiologic mechanism of disease? Am J Respir Crit Care Med 1999; 160: 1-9. 
2 Beckman JS, Beckman TW, Chen J, et al. Apparent hydroxyl radical production by peroxynitrite: implications for endothelial injury from nitric oxide and superoxide. Proc Natl Acad Sci USA 1990; 87: 1620-1624.

3 Eiserich JP, Hristova M, Cross CE, et al. Formation of nitric oxidederived inflammatory oxidants by myeloperoxidase in neutrophils. Nature 1998; 391: 393-397.

4 Beckman JS, Koppenol WH. Nitric oxide, superoxide, and peroxynitrite: the good, the bad, and ugly. Am J Physiol 1996; 271: C1424-C1437.

5 Ichinose M, Sugiura $H$, Yamagata $S$, et al. Increase in reactive nitrogen species production in chronic obstructive pulmonary disease airways. Am J Respir Crit Care Med 2000; 162: 701-706.

6 Sugiura H, Ichinose M, Tomaki M, et al. Quantitative assessment of protein-bound tyrosine nitration in airway secretions from patients with inflammatory airway disease. Free Radic Res 2004; 38: 49-57.

7 Saleh D, Ernst P, Lim S, et al. Increased formation of the potent oxidant peroxynitrite in the airways of asthmatic patients is associated with induction of nitric oxide synthase: effect of inhaled glucocorticoid. FASEB J 1998; 12: 929-937.

8 van der Vliet A, Nguyen MN, Shigenaga MK, et al. Myeloperoxidase and protein oxidation in cystic fibrosis. Am J Physiol Lung Cell Mol Physiol 2000; 279: L537-L546.

9 Saleh D, Barnes PJ, Giaid A. Increased production of the potent oxidant peroxynitrite in the lungs of patients with idiopathic pulmonary fibrosis. Am J Respir Crit Care Med 1997; 155: 1763-1769.

10 Ye YZ, Strong M, Huang ZQ, et al. Antibodies that recognize nitrotyrosine. Methods Enzymol 1996; 269: 201-209.

11 Riccardi VM, Maragos VA. The pathophysiology of neurofibromatosis. I. Resistance in vitro to 3-nitrotyrosine as an expression of the mutation. In Vitro 1980; 16: 706-714.

12 MacLean SJ, Huber RE. The effects of DL-p-fluorophenylalanine and L-3-nitrotyrosine on the growth and biochemistry of the Taper liver tumor. Cancer Res 1971; 31: 1669-1672.

13 Eiserich JP, Estevez AG, Bamberg TV, et al. Microtubule dysfunction by posttranslational nitrotyrosination of $\alpha$-tubulin: a nitric oxide-dependent mechanism of cellular injury. Proc Natl Acad Sci USA 1999; 96: 6365-6370.

14 Kaur H, Halliwell B. Evidence for nitric oxide-mediated oxidative damage in chronic inflammation. Nitrotyrosine in serum and synovial fluid from rheumatoid patients. FEBS Lett 1994; 350: 9-12.

15 Skinner KA, Crow JP, Skinner HB, et al. Free and proteinassociated nitrotyrosine formation following rat liver preservation and transplantation. Arch Biochem Biophys 1997; 342: 282-288.

16 Fukuyama N, Takebayashi $\mathrm{Y}$, Hida M, et al. Clinical evidence of peroxynitrite formation in chronic renal failure patients with septic shock. Free Radic Biol Med 1997; 22: 771-774.
17 Beal MF, Ferrante RJ, Browne SE, et al. Increased 3-nitrotyrosine in both sporadic and familial amyotrophic lateral sclerosis. Ann Neurol 1997; 42: 644-654.

18 Romanska HM, Polak JM, Coleman RA, et al. iNOS gene upregulation is associated with the early proliferative response of human lung fibroblasts to cytokine stimulation. J Pathol 2002; 197: 372-379.

19 Hsieh YS, Wang HC, Tseng TH, et al. Gaseous nitric oxide-induced 8-nitroguanine formation in human lung fibroblast cells and cellfree DNA. Toxicol Appl Pharmacol 2001; 172: 210-216.

20 Zhu YK, Liu XD, Skold MC, et al. Cytokine inhibition of fibroblastinduced gel contraction is mediated by PGE2 and NO acting through separate parallel pathways. Am J Respir Cell Mol Biol 2001; 25: 245-253.

21 Elsdale T, Bard J. Collagen substrata for studies on cell behavior. J Cell Biol 1972; 54: 626-637.

22 Mio T, Adachi Y, Romberger DJ, et al. Regulation of fibroblast proliferation in three dimensional collagen gel matrix. In Vitro Cell Dev Biol 1996; 32: 427-433.

23 Sugiura H, Liu X, Kobayashi T, et al. Reactive nitrogen species augment fibroblast-mediated collagen gel contraction, mediator production, and chemotaxis. Am J Respir Cell Mol Biol 2006; 34: 592-599.

24 Boyden S. The chemotactic effect of mixtures of antibody and antigen on polymorphonuclear leukocytes. J Exp Med 1962; 115 453-466.

25 Rennard SI, Hunninghake GW, Bitterman PB, et al. Production of fibronectin by the human alveolar macrophage: mechanism for the recruitment of fibroblasts to sites of tissue injury in interstitial lung diseases. Proc Natl Acad Sci USA 1981; 78: 7147-7151.

26 Yoshida M, Romberger DJ, Illig MG, et al. Transforming growth factor- $\beta$ stimulates the expression of desmosomal proteins in bronchial epithelial cells. Am J Respir Cell Mol Biol 1992; 6: 439-445.

27 Wang H, Liu X, Umino R, et al. Cigarette smoke inhibits human bronchial epithelial cell repair processes. Am J Respir Cell Mol Biol 2001; 25: 772-779.

28 Carnevali S, Nakamura Y, Mio T, et al. Cigarette smoke extract inhibits fibroblast-mediated collagen gel contraction. Am J Physiol 1998; 274: 591-598.

29 Sugiura $\mathrm{H}$, Ichinose $\mathrm{M}$, Oyake $\mathrm{T}$, et al. Role of peroxynitrite in airway microvascular hyperpermeability during late allergic phase in guinea pigs. Am J Respir Crit Care Med 1999; 160: 663-671.

30 Ichikawa T, Sugiura H, Koarai A, et al. Peroxynitrite augments fibroblast-mediated tissue remodeling via myofibroblast differentiation. Am J Physiol Lung Cell Mol Physiol 2008; 295: L800-L808. 